Int. J. Electrochem. Sci., 13 (2018) 9531 - 9550

\title{
Anodization of Aluminum in Highly Viscous Phosphoric Acid. PART 2: Investigation of Anodic Oxide Formation and Dissolution Rates
}

\author{
Lissy Berndt $^{1,2}$, Malte Kleemeier ${ }^{1}$, Karsten Thiel $^{1}$, Malte Burchardt ${ }^{1}$, Andreas Hartwig ${ }^{1,2, *}$ \\ ${ }^{1}$ Fraunhofer Institute for Manufacturing Technology and Advanced Materials IFAM, Wiener Straße \\ 12, D-28359 Bremen, Germany \\ ${ }^{2}$ University of Bremen, Department 2 Biology/Chemistry, Leobener Str. 2, D-28359 Bremen, \\ Germany \\ *E-mail: Andreas.hartwig@ifam.fraunhofer.de
}

doi: $10.20964 / 2018.10 .17$

Received: 10 May 2018 / Accepted: 2 July 2018 / Published: 1 September 2018

\begin{abstract}
A novel self-sticking adhesive tape for the local anodization of aluminum that can be removed without residue after anodization was developed. The extremely high viscosity of the electrolyte used in the anodization tape is the main difference to conventional bath anodization in aqueous phosphoric acid. Through the application of a step-like voltage program with abrupt changes in the anodization voltage, sublayers within the porous part of the anodic oxide were formed and then examined using transmission electron microscopy (TEM). The sublayers enable an estimation of the oxide formation and dissolution rates of bath and tape anodization. Both rates depend on the anodization voltage. At the beginning of the anodization process, the oxide formation rates for bath anodization and tape anodization were very similar. At a voltage of $25 \mathrm{~V}$, a formation rate of $0.9 \mathrm{~nm} \mathrm{~s}^{-1}$ was obtained for bath anodization, compared to $0.8 \mathrm{~nm} \mathrm{~s}^{-1}$ for tape anodization. However, the formation rate for the anodization tape slows down considerably in the later stages of anodization. This effect, which was not found for bath anodization, can be attributed to a local aging of the highly viscous electrolyte used for the anodization tape. Another special feature of the anodization tape is a very low rate of chemical oxide dissolution $\left(\leq 0.04 \mathrm{~nm} \mathrm{~s}^{-1}\right)$. In contrast, dissolution rates in the range of 0.1 to $\geq 0.2 \mathrm{~nm} \mathrm{~s}^{-1}$ were found for bath anodization, which are typical for strongly dissolving electrolytes such as phosphoric acid.
\end{abstract}

Keywords: aluminum, tape anodization, phosphorous acid, porous anodic oxide layer, oxide formation and dissolution rate

$\underline{\text { FULL TEXT }}$ 
(C) 2018 The Authors. Published by ESG (www.electrochemsci.org). This article is an open access article distributed under the terms and conditions of the Creative Commons Attribution license (http://creativecommons.org/licenses/by/4.0/). 